\title{
Supplementary Materials
}

\section{Results of Poisson Regression}

3 Poisson regression coefficients, $\beta$, of the three Poisson Regression models are summarized 4 in Table $\mathbf{S 1}$. 
Table S1: Results of Poisson regression, $\beta$, estimated from three Poisson Regression models. Here, $*$ denotes $p$-value $\in(0.01,0.1], * *$ denotes $p$-value $\in(0.001,0.01]$ and $* * *$ denotes $p$-value $<0.001$.

\begin{tabular}{|c|c|c|c|c|c|c|}
\hline \multirow[t]{13}{*}{ Dengue } & $\operatorname{Lag}(\tau)$ & Coeff. of $\operatorname{MEI}\left(\beta_{1}\right)$ & $95 \% \mathrm{CI}$ & $R^{2}$ & $p$-value & signf. \\
\hline & 0 & 0.1837 & {$[0.1047,0.2627]$} & 0.05474 & $5.147 \mathrm{e}-06$ & $* * *$ \\
\hline & 1 & 0.2225 & {$[0.1424,0.3025]$} & 0.07863 & $5.133 \mathrm{e}-08$ & $* * *$ \\
\hline & 2 & 0.2820 & {$[0.2003,0.3638]$} & 0.12073 & $1.385 \mathrm{e}-11$ & $* * *$ \\
\hline & 3 & 0.3417 & {$[0.2580,0.4253]$} & 0.16859 & $1.213 \mathrm{e}-15$ & $* * *$ \\
\hline & 4 & 0.3555 & {$[0.2683,0.4428]$} & 0.17237 & $1.376 \mathrm{e}-15$ & $* * *$ \\
\hline & 5 & 0.3507 & {$[0.2602,0.4412]$} & 0.16035 & $3.137 \mathrm{e}-14$ & $* * *$ \\
\hline & 6 & 0.3065 & {$[0.2146,0.3984]$} & 0.12191 & $6.203 \mathrm{e}-11$ & $* * *$ \\
\hline & 7 & 0.2780 & {$[0.1842,0.3718]$} & 0.09853 & $6.216 \mathrm{e}-09$ & $* * *$ \\
\hline & 8 & 0.2519 & {$[0.1575,0.3463]$} & 0.08021 & $1.708 \mathrm{e}-07$ & $* * *$ \\
\hline & 9 & 0.2724 & {$[0.1774,0.3674]$} & 0.09281 & $1.923 \mathrm{e}-08$ & $* * *$ \\
\hline & 10 & 0.2284 & {$[0.1344,0.3224]$} & 0.06753 & $1.921 \mathrm{e}-06$ & $* * *$ \\
\hline & 11 & 0.1874 & {$[0.0943,0.2805]$} & 0.04665 & $7.927 \mathrm{e}-05$ & $* * *$ \\
\hline \multirow[t]{13}{*}{ GBS } & $\overline{\operatorname{Lag}(\tau)}$ & "Coeff. of $\operatorname{MEI}\left(\beta_{2}\right)$ & $95 \% \mathrm{CI}$ & 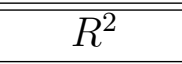 & $\overline{p \text {-value }}$ & signf. \\
\hline & 0 & 0.0438 & {$[-0.0361,0.1238]$} & $9.709 \mathrm{e}-03$ & 0.2827 & \\
\hline & 1 & -0.0041 & {$[-0.0852,0.0770]$} & $8.341 \mathrm{e}-05$ & 0.9208 & \\
\hline & 2 & -0.0151 & {$[-0.0978,0.0675]$} & $1.088 \mathrm{e}-03$ & 0.7200 & \\
\hline & 3 & -0.0172 & {$[-0.1015,0.0670]$} & $1.376 \mathrm{e}-03$ & 0.6884 & \\
\hline & 4 & -0.0030 & {$[-0.0894,0.0835]$} & $3.898 \mathrm{e}-05$ & 0.9462 & \\
\hline & 5 & 0.0139 & {$[-0.0750,0.1028]$} & $8.245 \mathrm{e}-04$ & 0.7595 & \\
\hline & 6 & 0.0206 & {$[-0.0700,0.1112]$} & $1.750 \mathrm{e}-03$ & 0.6561 & \\
\hline & 7 & 0.0469 & {$[-0.0459,0.1396]$} & $8.661 \mathrm{e}-03$ & 0.3223 & \\
\hline & 8 & 0.0848 & {$[-0.0096,0.1792]$} & $2.743 \mathrm{e}-02$ & 0.0785 & $*$ \\
\hline & 9 & 0.1137 & {$[0.0185,0.2088]$} & $4.929 \mathrm{e}-02$ & 0.0192 & * \\
\hline & 10 & 0.1139 & {$[0.0185,0.2092]$} & $4.930 \mathrm{e}-02$ & 0.0192 & $*$ \\
\hline & 11 & 0.0738 & {$[-0.0207,0.1684]$} & $2.124 \mathrm{e}-02$ & 0.1261 & \\
\hline \multirow[t]{13}{*}{$\overline{\mathrm{GBS}}$} & $\overline{\operatorname{Lag}(\tau)}$ & "Coeff. of Dengue $\left(\beta_{3}\right)$ & $95 \% \mathrm{CI}$ & 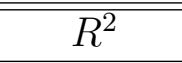 & $p$-value & signf. \\
\hline & 0 & -0.0146 & {$[-0.0306,0.0014]$} & 0.0279 & 7.436e-02 & $*$ \\
\hline & 1 & -0.0067 & {$[-0.0222,0.0088]$} & 0.0062 & $3.968 \mathrm{e}-01$ & \\
\hline & 2 & 0.0103 & {$[-0.0041,0.0247]$} & 0.0160 & $1.621 \mathrm{e}-01$ & \\
\hline & 3 & 0.0160 & {$[0.0018,0.0302]$} & 0.0393 & $2.737 \mathrm{e}-02$ & $*$ \\
\hline & 4 & 0.0134 & {$[-0.0013,0.0280]$} & 0.0263 & $7.309 \mathrm{e}-02$ & * \\
\hline & 5 & 0.0280 & {$[0.0141,0.0419]$} & 0.1211 & $8.017 \mathrm{e}-05$ & $* * *$ \\
\hline & 6 & 0.0327 & {$[0.0191,0.0463]$} & 0.1682 & $2.479 \mathrm{e}-06$ & $* * *$ \\
\hline & 7 & 0.0289 & {$[0.0149,0.0428]$} & 0.12706 & $5.191 \mathrm{e}-05$ & $* * *$ \\
\hline & 8 & 0.0098 & {$[-0.0055,0.0252]$} & 0.0134 & $2.104 \mathrm{e}-01$ & \\
\hline & 9 & 0.0140 & {$[-0.0011,0.0291]$} & 0.0282 & $6.882 \mathrm{e}-02$ & * \\
\hline & 10 & -0.0054 & {$[-0.0221,0.0112]$} & 0.0037 & $5.228 \mathrm{e}-01$ & \\
\hline & 11 & 0.0024 & {$[-0.0137,0.0184]$} & 0.0008 & $7.718 \mathrm{e}-01$ & \\
\hline
\end{tabular}

